\title{
The Cost of Gendered Attitudes on a Female Candidate: Evidence from Google Trends
}

\author{
Raphael Corbi \\ Pedro PicchetTi
}

WORKING PAPER SERIES № 2020-08 


\title{
The Cost of Gendered Attitudes on a Female Candidate: Evidence from Google Trends
}

\author{
Raphael Corbi (rcorbi@usp.br) \\ Pedro Picchetti (pedrop3@al.insper.edu.br)
}

\begin{abstract}
:
How much can negative attitudes towards women affect voting for a female candidate on a major election? We measure gender animus by calculating a proxy based on Google search queries that include gender-charged language. Such approach likely elicits socially sensitive attitudes by limiting the concern of social censoring, circumventing usual difficulties associated with survey-based measurements. We compare the proxy to Hillary Clinton's vote share in the presidential election of 2016, controlling for the vote share of the previous Democratic presidential candidate, Barack Obama. Our results indicate that a one standard deviation increase in our proxy is associated with a 2 percentage points relative loss for Hillary and suggest that online-based observable behavior can be useful for measuring different kinds of hard-to-measure social attitudes.
\end{abstract}

Keywords: Gender, Discrimination, Election, Google

JEL Codes: D72, J16, J7 


\title{
The Cost of Gendered Attitudes on a Female Candidate: Evidence from Google Trends
}

\author{
Raphael Corbi* $\quad$ Pedro Picchetti ${ }^{\dagger}$
}

June 1,2020

\begin{abstract}
How much can negative attitudes towards women affect voting for a female candidate on a major election? We measure gender animus by calculating a proxy based on Google search queries that include gender-charged language. Such approach likely elicits socially sensitive attitudes by limiting the concern of social censoring, circumventing usual difficulties associated with survey-based measurements. We compare the proxy to Hillary Clinton's vote share in the presidential election of 2016, controlling for the vote share of the previous Democratic presidential candidate, Barack Obama. Our results indicate that a one standard deviation increase in our proxy is associated with a 2 percentage points relative loss for Hillary and suggest that online-based observable behavior can be useful for measuring different kinds of hard-to-measure social attitudes.
\end{abstract}

Keywords: Gender, Discrimination, Election, Google.

JEL Codes: D72, J16

\footnotetext{
*Av. Prof. Luciano Gualberto 908, São Paulo. Universidade de São Paulo. E-mail: rcorbi@usp.br
} ${ }^{\dagger}$ Insper. E-mail: pedrop3@al.insper.edu.br 


\section{Introduction}

Do gendered attitudes cost a female candidate a substantial amount of votes? This question has been reignited after Hillary Clinton's defeat to Donald Trump in the 2016 presidential election. By assessing this issue we can learn about the extension of gender animus in today's society and its consequences concerning the female underrepresentation in governments. For example, women currently hold 19.3 percent of seats in the US House of Representatives and 21.0 percent in the Senate.

The literature shows that women elected to office affect the provision of public goods (Corrêa, 2014) and reduces corruption (Brollo and Troiano, 2016). On the other hand, female candidates are less likely to be reelected and to run again for office after losing an election (Novaes, 2017; Wasserman, 2018).

Whether male voters will vote or not for a female presidential candidate is one of the many questions in social sciences for which the answer is not straightforward due to social desirability bias. The accuracy of survey results regarding sensitive questions has been widely debated by researchers (Berinski, 1999; Tourangeau and Yan, 2007) and have produced inconclusive results (Mas and Moretti, 2008; Piston, 2010). A closely related work investigated the role of racial prejudice in elections. Using an alternative non-survey measure of racial animus based on google search data, Stephens-Davidowitz (2014) estimates that Barack Obama prejudice in the US appears to have cost Obama roughly four percentage points of the national popular vote in both 2008 and 2012, 1.5 to 3 times larger than survey-based estimates.

We believe that the nature of online search - mostly alone and anonymous - likely elicits socially sensitive attitudes by limiting the concern of social censoring and can overcome the difficulties which arise from measurement error in survey based data (Conte and Sobiesk, 2007). Furthermore, aggregating information from millions of searches, Google can meaningfully reveal social patterns across different geographical regions.

We follow Stephens-Davidowitz (2014) and define a gender-charged search rate as the percentage of searches for the word ["Word 1"] and its plural between 2012 and 2015 at media-market level. ${ }^{1}$ The epithet we chose is one of the most common sexist slurs used online and it is highly associated with messages that reinforce negative female stereotypes and enforce the negative sentiment of these messages (Felmlee et al., 2019; Wu, 2018). We do not include data from 2016 in order to avoid reverse causality, that is, a potential increase in exposition of Hillary Clinton after the campaign affecting the online search of offensive

\footnotetext{
${ }^{1}$ This paper uses Google search terms containing sensitive language. We use coded language to refer to such words in the main text and report the actual terms in the appendix.
} 
language towards women.

Gender-charged search rate is a significant, negative predictor of Hillary's 2016 vote shares, controlling for Obama's 2012 share. The result is robust when we add controls for changes in unemployment rates, home-state candidate preference, Census division fixed effects, demographic controls, and long-term trends in Democratic voting. The estimated effect is virtually unchanged when we account for Google search rates of other terms that are moderately correlated with search rate for ["Word 1"] but not direct evidence of gender animus. $^{2}$

Our preferred specification indicates that a one standard deviation increase in gendered attitudes towards women cost Hillary 2 percentage points of the national popular vote in 2016. A non-gender explanation for the results might be that areas with higher gendercharged search rates became more conservative during this time period. However, there is not a significant relationship between an area's gender-charged search rate and changes in the Democratic House vote shares over the same time period.

Our paper is organized as follows. In Section 2 we justify our choice to use Google data as a measure for gendered attitudes towards women. In section 3 we explain our empirical strategy and present the main results.

\section{Google search data as proxy for gendered attitudes}

In 2013, nearly $80 \%$ of American households accessed the internet, with large numbers from all demographic groups (ACS, 2015). The bulk of online searches in the US is performed on Google (Burns, 2007). The nature of online search - mostly alone and anonymous - likely elicits socially sensitive attitudes by limiting the concern of social censoring. ${ }^{3}$ Google search data is also a strong predictor of regional differences in interests. Stephens-Davidowitz (2014) shows that the search rate for the word "God", "Gun" and "Jewish" predict over $60 \%$ of the variation in the percent of US states residents who believe in God, own a gun or are jewish, respectively. Consequently, the use of google data in empirical work has vastly expanded in recent years across social and medical sciences (Seifter et al, 2010; Varian and Choi, 2010).

We follow Stephens-Davidowitz (2014) and define a media-market j's gender-charged search rate as the percentage of searches for the word ["Word 1"] and its plural between

\footnotetext{
${ }^{2}$ In particular, we control for search rates for "Prostitute(s)" and ["Word 2"], the term used by StephensDavidowitz (2014) to measure racial animus online.

${ }^{3}$ Conte and Sobiesk (2007) conduct a survey in which $92,4 \%$ of subjects used Google as their main search tool and $73 \%$ revealed having searched for content they would not wish to share with their parents or future employers.
} 
Figure 1: Google searches across time and geography: 2012-2015.

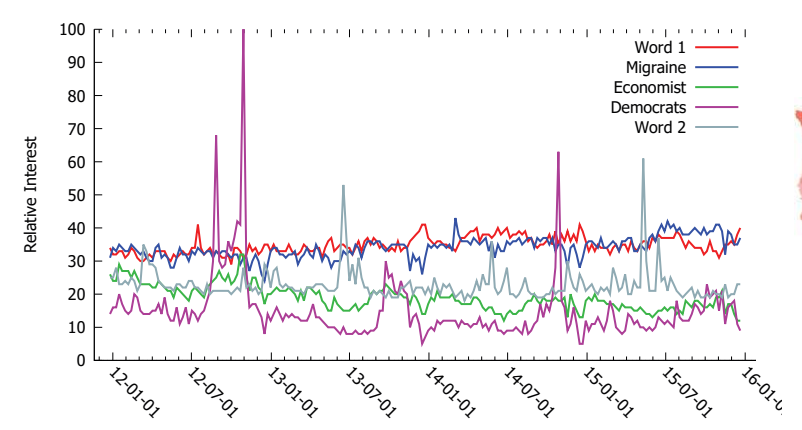

(a) across time

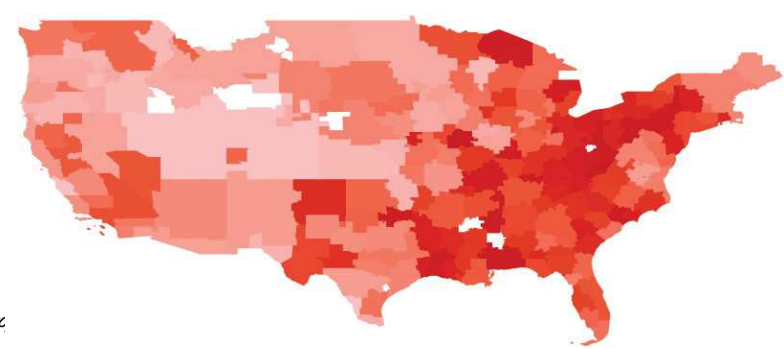

(b) geography

Note: Panel (a) shows us the relative interest of searches for our "[Word 1]" compared to other commonly searched words in Google from 2012 to 2015. Panel (b) maps the search volume for "[Word 1]" from 2012 to 2015 at the media market level. Darker areas indicate higher search volume. White areas indicate media markets for which data is not available.

2012 and 2015 at media market $j$.

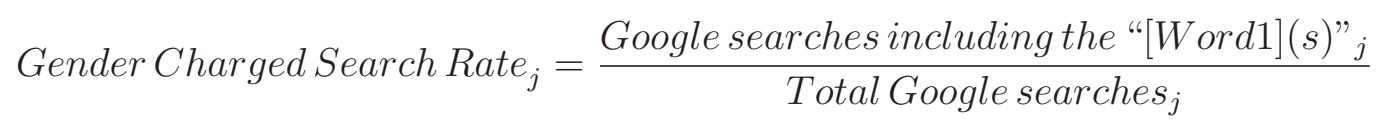

Google Trends provides a relative index of the volume of Google queries by geographic location and category. Index measures are scaled separately for each state in each year, so that the popularity of a topic relative to another is comparable across states and time.

According to Felmlee et al. (2019), the epithet we chose is one of the most common sexist slurs used online and it is highly associated with messages that reinforce negative female stereotypes and enforce the negative sentiment of these messages. ${ }^{4}$

The epithet is a common word in Google searches: Figure 1(a) reports the relative search level frequency overtime. Relative interest for the epithet has been roughly the same as for "Migraine" and higher - for the most of the time period - than for the words "Economist", "Democrat" and "[Word 2]", the term used by Stephens-Davidowitz (2014) to calculate the racially charged search rate. Figure 1(b) shows search volume for "[Word 1]" at the media market level. Darker areas signify higher search volume. The search rate was highest in West Virginia; Kentucky; Arkansas; Mississippi and Alaska; and lowest in Minnesota; Hawaii; California; Utah; Hawaii and District of Columbia. White areas signify media markets without data. Alaska and Hawaii, for which data is not available, are not shown.

We obtain data from Google Trends for all 50 states and 179 of 210 media markets,

\footnotetext{
${ }^{4}$ Felmlee et al.(2019) argue that identifying a woman as a "[Word 1]" means that she falls far out of line with the norm of sexual inexperience. This epithet ranks within the top 20 of all types of curse words used on Twitter (Wang et al, 2014) and one of the most predictive words of a post about a woman on the popular Economics Job Market Rumors forum (Wu, 2018).
} 
Figure 2: Gender-charged, racially charged Google search and \#MeToo movement support

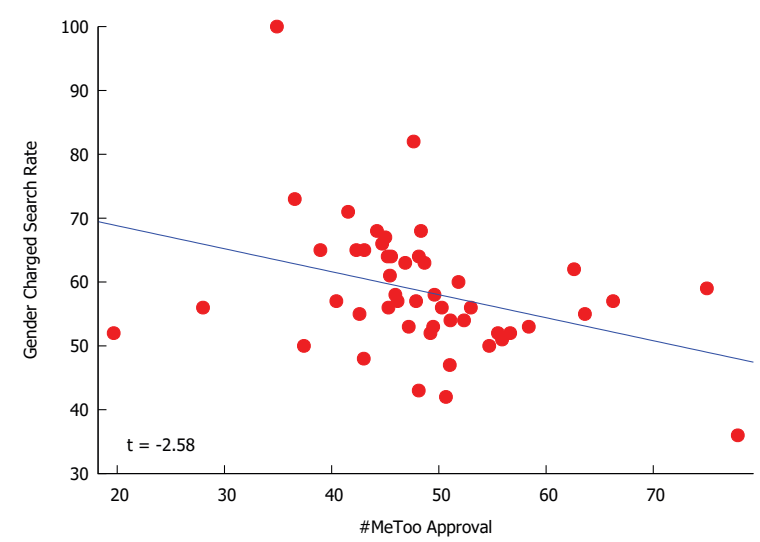

(a) proxy comparison

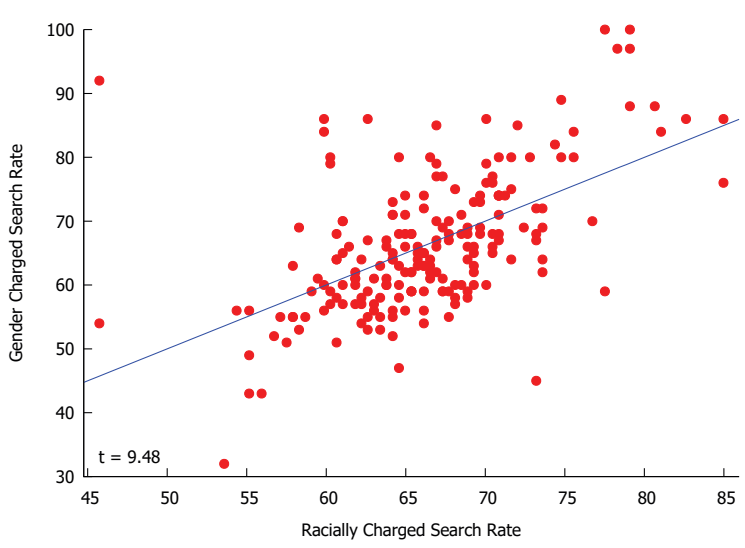

(b) gender vs racially-charged

Note: The $\mathrm{x}$-axis in panel (a) is average state approval rate of the \#MeToo movement from the 2018 wave of the American National Election Study (ANES). The x-axis in panel (b) is the measure of racism used in Stephen-Davidowitz (2014) - google search rate of "[Word 2]". The y-axis in panel (a) is the state's gender-charged search rate for the 49 states for which ANES data is available. The y-axis in panel (b) is the Google gender-charged search rate at the media market level.

encompassing more than $95 \%$ of American voters. ${ }^{5}$ Data for our demographic variables was obtained from the Census Bureau and the American Community survey, whereas the data regarding unemployment rates come from Local Area Unemployment Statistics. See Table 2 for a set of summary statistics, including Hillary's and Obama's support.

Table 1 shows the demographic predictors of the gender-charged search rate at the media market level. The demographic factor which correlates strongest with the gender-charged search rate is the percentage of population with a bachelor's degree. A 8 p.p. increase in college graduates is correlated with a one standard deviation decrease in the search rate. The elder and the veterans, on the other side, are more likely to search the term.

Figure 2(a) compares state-level gender-charged search rate with a measure of support of the \#MeToo movement from the 2018 wave of the American National Election Study (ANES). McConahay (1983) and Kinder and Sanders (1996) argue that prejudice manifests itself not only by stereotypes or offensive language, but also through resentment toward the minorities (e.g. resentment toward black students after affirmative action, backlash against female movements). The Google search rate has a correlation of -0.4 with ANES \#MeToo movement approval. Figure 2(b) plots the gender-charged vs racially charged search rate for the 50 states and the District of Columbia. The relationship is positive and highly statistically significant $(\mathrm{t}=9.48)$. Despite the high level of correlation, gender-charged and racially charged search rates are shown to measure different political attitudes as discussed in the next section.

\footnotetext{
${ }^{5}$ Google trends data were downloaded on 21/03/2019.
} 
Figure 3: Gender-charged search rate and female candidate support

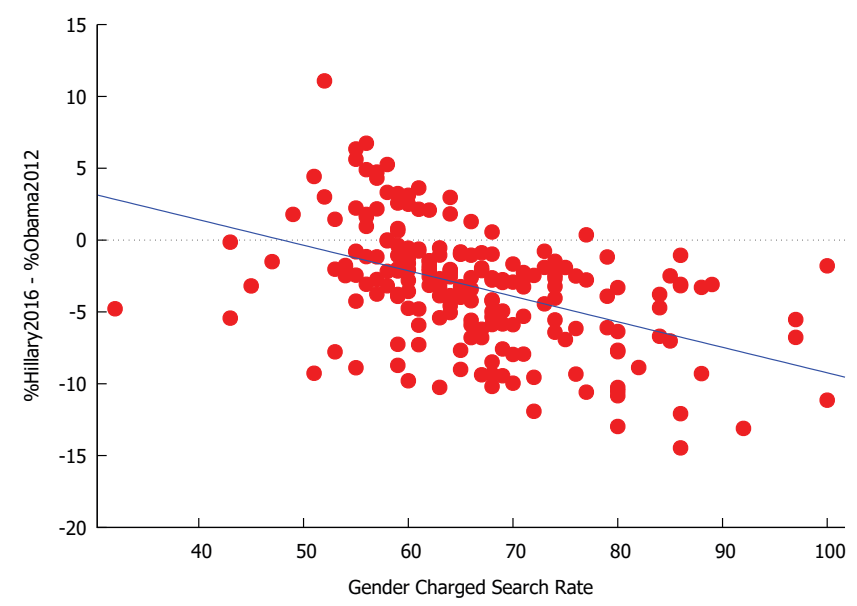

Note: The x-axis is the media market's gender-charged search rate. The y-axis is Hillary's 2016 share of two-party votes subtracted by Obama's 2012 share.

\section{$3 \quad$ Empirical strategy and main results}

In this section, we compare the gender-charged Google search proxy to the difference between an area's support for Hillary in 2016 and Obama in 2012. First we define \% Hillary2016 ${ }_{j}$ as the percent of total two-parties vote received by Hillary and \%Obama2012 $j$ as the percent of total two-parties vote received by Obama. Then $\left(\%\right.$ Hillary2016 - \%Obama2012) ${ }_{j}$ is meant to capture the relative preference for a female candidate compared to a male candidate.

Before adding a complete set of control variables we plot the correlation between $\left(\%\right.$ Hillary2016 - \%Obama2012) ${ }_{j}$ and Gender Charged Search Rate ${ }_{j}$ at the media market level. The relationship can be seen in Figure 3. Due to different electoral conditions in 2016 and 2012, Hillary had a worst performance than Obama at a national level (see Table 2). Yet visual inspection suggests that Hillary systematically loses more votes in media markets where the gender charge search rate is relatively higher.

A potential non-gender explanation for our correlational evidence might be that more conservative-oriented regions, with higher rates of gender and racially-charged search rates, were trending Republican in that time period, for reasons other than the gender of the candidates. If such alternative explanation were the main factor driving our results, one would expect other Democratic candidates to be similarly punished in areas with high gendercharged search rates around this time period. In Figure 4(a), we put this conjecture to the test and find no association between Gender Charged Search Rate ${ }_{j}$ and change in support for Obama from 2008 to 2012 across media markets. In Figure 4(b), we provide a placebo test for changes in state-level Democrat vote share in House races from 2016 to 2012 - same 
Figure 4: Gender-charged search rate and democrat support

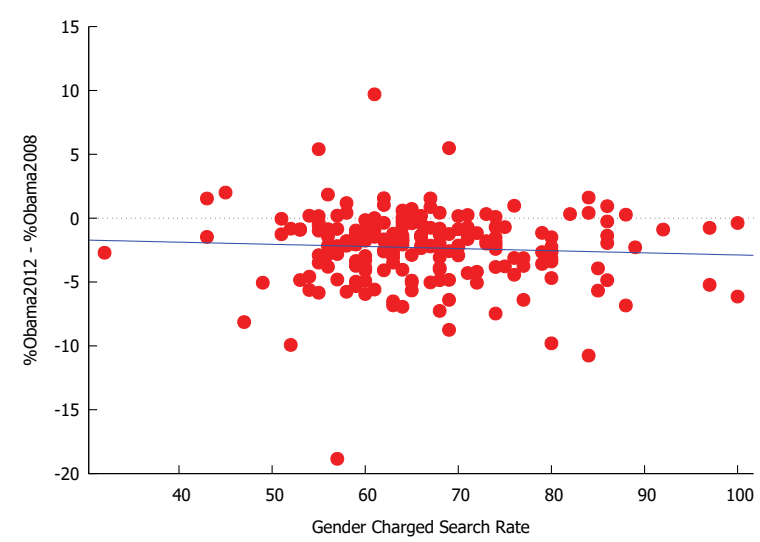

(a) Obama 2012 - Obama 2008

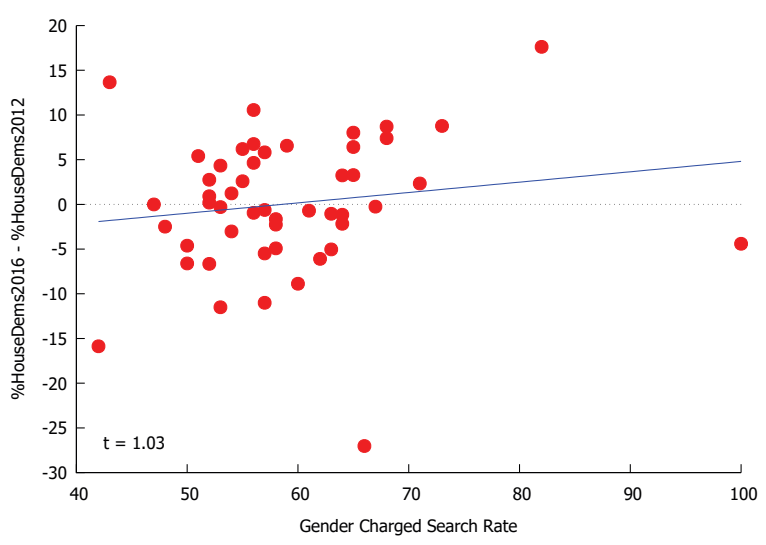

(b) HouseDems 2016 - HouseDems 2012

Note: The x-axis in both panels is the gender-charged search rate. The y-axis in panel (a) is Obama's 2012 share of two-party votes subtracted by Obama's 2008 share in a media market. The y-axis in panel (b) is the state-level Democrats' 2008 share of house of representatives two-party vote subtracted from Democrats' 2012 share.

year as the Presidential election we are interested in. ${ }^{6}$

We specify a regression model for change in Democrats' vote share at the media market level $j$ that exploits geographical variation in search rates. Specifically we assume that

$$
(\% \text { Hillary2016 }-\% \text { Obama2012 })_{j}=\beta_{0}+\beta_{1} \text { Gender Charged Search Rate } \text { C }_{j}+\phi X_{j}+\epsilon_{j}
$$

where $X_{j}$ are area-level controls that might influence change in the Democratic candidate support between the elections; $\beta_{0}$ is a country-wide popularity shock to the Democrats' popularity in 2016 and $\epsilon_{j}$ is the error term. Gender Charged Search Rate ${ }_{j}$ is normalized to its z-score, so that $\beta_{1}$ measures the impact of a one standard deviation increase in Gender Charged Search Rate ${ }_{j}$ on Hillary's vote share. All regressions are weighted by the 2012 total two-party votes. These geographic data are likely spatially correlated, and hence we report both standard errors clustered at the state level and corrected for spatial correlation in square brackets. Following Conley (1999), we allow for spatial dependence of an unknown form.

Table 3 - panel (a) reports the results. All columns include two controls known to consistently influence the presidential vote choice, namely Home State $_{j}$ that takes the value 1 for the state of New York, -1 for the states of Illinois and Arizona and 0 otherwise; and unemployment rates in 2011, 2012, 2015 and 2016 as proxies for economic performance (Campbell, 1992). Column (1) shows that a one standard deviation increase in a media's market gendercharged search rate (normalized to its z-score) is associated with 2.0 percentage points fewer

\footnotetext{
${ }^{6}$ Figure 4(b) plots data aggregated at the state level because some media-markets cross state borders.
} 
Hillary votes. Column (2) adds Census divisions fixed effects and the estimate remains virtually unchanged. In column (3), our main estimate remains negative and significant albeit one half lower in magnitude as we add the demographic controls found in Table 1. The reduction in the coefficient as these controls are added could be partially explained by our Google-based proxy for gendered attitudes having measurement error.

In Columns (4)-(6) we reproduce the results from (1)-(3) but add normalized Google search volume for "[Word 2](s)" as a control, due to the presence of a black candidate, and for "Prostitute(s)" in an effort to reduce measurement error in the proxy and assess the stability of our estimates. The latter is likely correlated with our search term, but less likely to express gendered attitudes. All estimates are virtually unchanged.

Panels (b) and (c) examines non-gender competing explanations more systematically by introducing different dependent variables. Panel (b) shows that, upon adding the controls, there still is not a significant relationship between gender-charged search rate and change in Obama support from 2008 to 2012, as suggested in Figure 4(a). The coefficients in Panel (c) are very similar to the corresponding coefficients in Panel (a), consistent with the view our estimates capture something specific to the 2016 election and not differential voting pre-trends across parties. Taking as a whole, these results are consistent with a causal interpretation between gendered attitudes and electoral costs to a female candidate. ${ }^{7}$

The literature exploring the effects of gender on political behavior shows that female turnout has been consistently increasing (Atkeson, 2003), especially when female candidates particularly identify their femininity as part of the campaign. Thus, the estimated effects of gendered attitudes on Hillary's vote share may be also due to women being less likely to turnout to vote as a response to a female candidate in areas where gender animus is more pronounced or due to voters motivated to turnout to oppose a female candidate. Table 4 tests for this possibility by investigating the relationship between the change in turnout at media-market level and the gender-charged search rate. Across all specifications, the effect is virtually zero indicating that gender animus did not play an important role in changes in turnout across elections.

\section{Conclusion}

Hillary Clinton became the first woman to be a major U.S. political party's nominee for president. After failing to defeat Donald Trump in the election, many political analysts and pundits claimed that gendered attitudes played a major role in the outcome in 2016.

\footnotetext{
${ }^{7}$ As a note of caution, an alternative interpretation is that voters that are more liberal on gender may be voting for Hillary at a higher rate.
} 
A systematic investigation of this kind of claims by eliciting such socially sensitive attitudes in surveys is difficult due to social censoring. We argue that the anonymous nature of online search limits these concerns, and draw on earlier work on the use of Google data to measure the role of racism in politics (Stephen-Davidowitz, 2014).

Our results indicate that negative attitudes toward women are directly associated with Hillary's 2016 electoral performance and suggest that online-based observable behavior can be useful for measuring different kinds of hard-to-measure social attitudes. 


\section{References}

Atkeson, Lonna Rae. (2003) "Not All Cues Are Created Equal: The Conditional Impact of Female Candidates on Political Engagement." The Journal of Politics. 65.4 :1040- 1061

Berinsky, Adam J. (1999) "The two faces of public opinion." American Journal of Political Science.Vol 43, No 4: 1209-1230.

Brollo, Fernanda \& Troiano, Ugo. (2016) "What happens when a woman wins an election? Evidence from close races in Brazil." Journal of Development Economics. Vol 122: 28-45.

Colella, Fabrizio; Lalive, Rafael; Sakalli, Seyhun Orcan; \& Thoenig, Mathias. (2019) "Inference with Arbitrary Clustering" IZA Discussion Paper n. 12584

Conti, Gregory \& Sobiesk, Edward. (2007) "An Honest Man has Nothing to Fear: User Perceptions on Web based Information Disclosure." Symposium On Usable Privacy and Security.

Corrêa, Gabriel Barreto. (2014) "The size of local legislatures and women's political representation: evidence from Brazil". 2014. Dissertação de Mestrado em Teoria Econômica, Universidade de São Paulo, São Paulo. doi:10.11606/D.12.2014.tde-29082014-195909.

Felmlee, D., Inara Rodis, P. \& Zhang, A. (2019) "Sexist Slurs: Reinforcing Feminine Stereotypes Online.” Sex Roles (2019). https://doi.org/10.1007/s11199-019-01095-z

Kinder, Donald, \& Sanders, Lynn. (1996) "American politics and political economy. Divided by color: Racial politics and democratic ideals." University of Chicago Press.

Mas, Alexandre, \& Moretti, Enrico. (2009) "Racial Bias in the 2008 Presidential Election." American Economic Review: Paper 83 Proceedings.Vol 99, No 2 : 323-329.

McConahay, John. (1983) "Modern racism and modern discrimination: The effects of race, racial attitudes, and context on simulated hiring decisions." Personality and Social Psychology Bulletin. Vol 9, No 4: 551-558

Novaes, Lucas. (2017) "The Exit Trap: Gender Differences in Political Perseverance." Available at SSRN: https://ssrn.com/ abstract=3031924 or http://dx.doi.org/10.2139/ssrn.3031924

[dataset] Picchetti, Pedro (2020), "Dataset - Gendered Attitudes", Mendeley Data, v1 http://dx.doi.org/10.17632/mc35j5zyrf.1

Piston, Spencer. (2010) "How Explicit Racial Prejudice Hurt Obama in the 2008 Election." Political Behavior. Vol 32, No 4: 431-451.

Seifter, Ari, Schwarzwalder, Alison, Geis, Kate \& Aucott, John. (2010) "The utility of "Google Trends" for epidemiological research: Lyme disease as an example." Geospatial Health. Vol 4, No 2: $135-137$.

Stephens-Davidowitz, Seth. (2014) "The cost of racial animus on a black candidate: Evidence using Google search data." Journal of Public Economics. Vol 118: 26-40.

Tourangeau, R., \& Yang, T. (2007) "Sensitive Questions in Surveys." Phsycological Bulletin. Vol 133, No 5: 859-883.

Varian, Hal, \& Choi, H.(2010) "Predicting the Present with Google trends." Economic Record. Vol 188, No 1: 2-9. 
Wu, Alice. (2018). Gendered Language on the Economics Job Market Rumors Forum. American Economic Association Papers and Proceedings. 108. 175-79. 10.1257/pandp.20181101. 
Table 1: Predictors of a media market's gender-charged search rate

\begin{tabular}{|c|c|c|c|c|}
\hline & $(1)$ & $(2)$ & $(3)$ & $(4)$ \\
\hline Percent age 65 or older & $\begin{array}{l}9.073^{* *} \\
(4.478)\end{array}$ & $\begin{array}{l}9.268^{* *} \\
(4.047)\end{array}$ & $\begin{array}{l}6.458 \\
(4.153)\end{array}$ & $\begin{array}{l}6.336^{*} \\
(3.757)\end{array}$ \\
\hline Percent w/ bachelor's degree & $\begin{array}{l}-8.837^{* * *} \\
(1.044)\end{array}$ & $\begin{array}{l}-8.340^{* * *} \\
(1.300)\end{array}$ & $\begin{array}{l}-8.166^{* * *} \\
(1.175)\end{array}$ & $\begin{array}{l}-7.662^{* * *} \\
(1.418)\end{array}$ \\
\hline Percent 18 to 34 & $\begin{array}{l}0.731 \\
(2.251)\end{array}$ & $\begin{array}{l}1.486 \\
(2.350)\end{array}$ & $\begin{array}{l}0.166 \\
(2.187)\end{array}$ & $\begin{array}{l}0.886 \\
(2.258)\end{array}$ \\
\hline Percent of veterans & - & - & $\begin{array}{l}6.852^{* * *} \\
(2.385)\end{array}$ & $\begin{array}{l}7.420^{* *} \\
(3.120)\end{array}$ \\
\hline Observations & 179 & 179 & 179 & 179 \\
\hline R-squared & 0.308 & 0.403 & 0.329 & 0.424 \\
\hline Census div. FE & & $\mathrm{x}$ & & $\mathrm{x}$ \\
\hline
\end{tabular}

Note: Standard errors clustered at the state level are in parentheses. The dependent variable is Gender-Charged Search Rate as defined in Section 2, normalized to its z-score. ${ }^{* * *},{ }^{* *}$ and ${ }^{*}$ indicate significance at the 1,5 and 10 percent critical level.

Table 2: Summary statistics

\begin{tabular}{lllll}
\hline \hline & Mean & SD & Min & Max \\
\cline { 2 - 5 } Gender Charged Search Rate & 66.34 & 10.85 & 32 & 100 \\
\%Kerry2004 & 43.43 & 9.42 & 19.89 & 70.06 \\
\%Obama2008 & 47.82 & 10.64 & 22.16 & 75.05 \\
\%Obama2012 & 45.48 & 11.40 & 19.66 & 76.87 \\
\%Hillary2016 & 42.21 & 12.75 & 17.67 & 79.38 \\
\%Obama2008 - \%Kerry2004 & 4.47 & 4.03 & -10.98 & 18.60 \\
\%Obama2012 - \%Obama2008 & -2.33 & 2.81 & -18.46 & 9.41 \\
\%Hillary 2016 - \%Hillary 2012 & -3.26 & 4.14 & -14.46 & 11.08 \\
\%Turnout2016 - \%Turnout2012 & 1.49 & 5.24 & -17.69 & 16.75 \\
\hline \hline
\end{tabular}

Note: All summary statistics are for the 179 media markets for which data on Gender Charged Search Rate and voting data are available. Gender Charged Search is defined Section 2. All candidate variables are that candidate's percentage points of two-party votes in a given year. Turnout is the total two-party presidential votes in a given year. 
Table 3: Gendered attitudes and vote share across elections

\begin{tabular}{|c|c|c|c|c|c|c|}
\hline & $(1)$ & $(2)$ & $(3)$ & $(4)$ & $(5)$ & $(6)$ \\
\hline \multirow{4}{*}{ Gender Charged Search } & \multicolumn{6}{|c|}{ Panel A - Dependent variable: \%Hillary2016 - \%Obama2012 } \\
\hline & -1.954 & -2.005 & -0.958 & -1.965 & -2.025 & -0.990 \\
\hline & $(0.404)^{* * *}$ & $(0.431)^{* * *}$ & $(0.409)^{* *}$ & $(0.405)^{* * *}$ & $(0.428)^{* * *}$ & $(0.411)^{* *}$ \\
\hline & {$[0.376]^{* * *}$} & {$[0.373]^{* * *}$} & {$[0.343]^{* * *}$} & {$[0.388]^{* * *}$} & {$[0.366]^{* * *}$} & {$[0.331]^{* * *}$} \\
\hline \multirow{4}{*}{ Gender Charged Search } & \multicolumn{6}{|c|}{ Panel B - Dependent variable: \%Obama2012 - \%Obama2008 } \\
\hline & -0.289 & -0.422 & -0.220 & -0.202 & -0.423 & -0.216 \\
\hline & $(0.294)$ & $(0.380)$ & $(0.316)$ & $(0.298)$ & $(0.380)$ & $(0.315)$ \\
\hline & {$[0.237]$} & {$[0.290]$} & {$[0.221]$} & {$[0.255]$} & {$[0.296]$} & [0.298] \\
\hline \multirow{4}{*}{ Gender Charged Search } & \multicolumn{6}{|c|}{ Panel C - Dependent Variable: \%Hillary2016 - \%Obama2008 } \\
\hline & -1.941 & -2.347 & -1.112 & -1.915 & -1.978 & -1.057 \\
\hline & $(0.565)^{* * *}$ & $(0.637)^{* * *}$ & $(0.537)^{* *}$ & $(0.426)^{* * *}$ & $(0.488)^{* * *}$ & $(0.552)^{*}$ \\
\hline & {$[0.488]^{* * *}$} & {$[0.508]^{* * *}$} & {$[0.416]^{* * *}$} & {$[0.518]^{* * *}$} & {$[0.498]^{* * *}$} & {$[0.451]^{* *}$} \\
\hline Observations & 179 & 179 & 179 & 179 & 179 & 179 \\
\hline Standard Controls & $\mathrm{x}$ & $\mathrm{x}$ & $\mathrm{x}$ & $\mathrm{x}$ & $\mathrm{x}$ & $\mathrm{x}$ \\
\hline Census div. FE & & $\mathrm{x}$ & $\mathrm{x}$ & & $\mathrm{x}$ & $\mathrm{x}$ \\
\hline Demographic Controls & & & $\mathrm{x}$ & & & $\mathrm{x}$ \\
\hline Google Controls & & & & $\mathrm{x}$ & $\mathrm{x}$ & $\mathrm{x}$ \\
\hline
\end{tabular}

Note: OLS regressions are weighted by two-party total presidential votes in the 2012 election. Gender Charged Search Rate is as defined in Section 2, normalized to its z-score. In panel (a), the dependent variable is Hillary's two-party vote share in 2016 minus Obama's two-party vote share in 2012. Home State takes value 1 for the states of New York and Massachusetts; value -1 for the states of Illinois and 0 otherwise. Standard controls are Home State and unemployment rates in 2011, 2012, 2015 and 2016. The dependent variable in Panel (b) is Obama's two-party vote share in 2012 minus its share in 2008. Home State take value -2 for Massachusetts; 1 for Illinois; 1 for Texas and 0 otherwise. The unemployment rates are from 2011, 2007 and 2008 (from Local Area unemployment Statistics). In panel (c), the dependent variable is Hillary's two-party vote share in 2016 minus Obama's two-party vote share in 2008. Home State takes value 1 for New York and Massachusetts, -1 for Illinois and 0 otherwise. Unemployment rates are from 2007, 2008 and 2015 (from Local Area unemployment Statistics). Demographic controls are percent with bachelor's degree, percent 65+, percent 18-34 and percent veteran(from American Community Survey 13-17). Google controls are normalized search volume for "Prostitute(s)" and "[Word 2]". Standard errors clustered at the state level are in parentheses. Conley standard errors are in brackets. ${ }^{* * *},{ }^{* *}$ and ${ }^{*}$ indicate significance at the 1,5 and 10 percent critical level. 
Table 4: Change in turnout (2012 - 2016) and gender-charged search rate

\begin{tabular}{lcccccc}
\hline \hline & \multicolumn{1}{c}{$(1)$} & $(2)$ & $(3)$ & $(4)$ & $(5)$ & $(6)$ \\
\cline { 2 - 7 } Gender Charged Search & 0.015 & 0.011 & 0.037 & 0.001 & 0.052 & 0.079 \\
& $(0.049)$ & $(0.050)$ & $(0.057)$ & $(0.045)$ & $(0.063)$ & $(0.064)$ \\
& {$[0.039]$} & {$[0.039]$} & {$[0.049]$} & {$[0.038]$} & {$[0.050]$} & {$[0.058]$} \\
& -2.455 & -3.439 & -3.498 & -2.407 & -3.165 & -3.223 \\
Home State & $(1.632)$ & $(0.940)^{* * *}$ & $(0.997)^{* * *}$ & $(1.591)$ & $(0.875)^{* * *}$ & $(0.915)^{* * *}$ \\
& {$[1.983]$} & {$[0.834]^{* * *}$} & {$[0.897]^{* * *}$} & {$[1.379]$} & {$[0.852]^{* * *}$} & {$[0.913]^{* * *}$} \\
Observations & 179 & 179 & 179 & 179 & 179 & 179 \\
R-Squared & 0.052 & 0.331 & 0.358 & 0.099 & 0.336 & 0.365 \\
Standard Controls & $\mathrm{x}$ & $\mathrm{x}$ & $\mathrm{x}$ & $\mathrm{x}$ & $\mathrm{x}$ & $\mathrm{x}$ \\
Census Div. FE & & $\mathrm{x}$ & $\mathrm{x}$ & & $\mathrm{x}$ & $\mathrm{x}$ \\
Demographic Controls & & & $\mathrm{x}$ & & $\mathrm{x}$ & $\mathrm{x}$ \\
Google Controls & & & & $\mathrm{x}$ & $\mathrm{x}$ & $\mathrm{x}$ \\
\hline \hline
\end{tabular}

Note: OLS regressions are weighted by two-party total presidential votes in the 2012 election. Dependent variable is the percentage change in the two-party vote share (2016-2012). Gender Charged Search Rate is as defined in Eq(1), normalized to its z-score. Home State takes value 1 for the state of New York; value -1 for the states of Chicago and Arizona; 0 otherwise. Standard controls are Home State and unemployment rates in 2011, 2012, 2015 and 2016. Demographic controls are percent with bachelor's degree, percent 65+, percent 18-34 and percent veteran. Google controls are normalized search volume for "Prostitute(s)" and "[Word 2]". Standard errors clustered at the state level are in parentheses. Conley standard errors are in brackets. ${ }^{* * *},{ }^{* *}$ and ${ }^{*}$ indicate significance at the 1,5 and 10 percent critical level.

\section{Appendix: Coding for offensive words}

\begin{tabular}{ll}
\hline Word & Code in text \\
\hline whore & Word 1 \\
nigger & Word 2 \\
\hline
\end{tabular}

